\title{
O Methodo nas Sciencias Sociaes (*)
}

\author{
Dr. A. de Sampaio Doria
}

Nunca a humanidade precisou, tanto como hoje, de consciencias que a illuminem. Em logar do scepticismo, que corróe e anniquila, as convicções sem eclipse, que removam montanhas, e construam. Os homens cujos passos não vão nem vêm, são como naus que perderam o leme numa tempestade, e ficaram á mercê dos vagalhões que as açoitem. Hoje, os povos só se salvarão das calamidades internas, como as ornnipotencias irresponsaveis, que, por toda parte, bramem como féras, ou das catastrophes internacionaes, como a que, neste momento, sacóde e ameaça conflagar o velho continente, se forem, no duro trato da vida, um viveiro de homens de cultura politica, de convicções inabalaveis, de absoluta inteireza moral.

Por isto não ha, e maiormente para nós, (o paiz mais cubiçado pelos imperialismos estrangeiros), problema de importancia igual ao da educação publica.

Já ninguem hoje crê na divisão do universo em dois mundos contraditorios : o mundo physico regido pr leis, e o mundo moral onde não haja causas nem effeitos. Não. O mundo tambem se rege por leis. O que fôr soará só é norma entre os que tiverem o cerebro vazio de senso, como o

$\left(^{*}\right)$ Conferencia proferida na aula inaugural dos cursos da Universidade de São Paulo, em 1936. 
azar que persiga não é senão ingenuidade das almas simples, ou superstição das intelligencias sem logica. A verdade é haver, por toda parte, causas e effeitos.

Ora, uma das leis mais certas na vida social é que as melhores instituições em povos cultos dão os peores resultados em povos sem cultura. Não é porque o presidencialismo floresça num paiz como os Estados Unidos, que haja de frutecer na Cafraria ou na Ethiopia. As mesmas causas só produzem os mesmos effeitos nas mesmas circumstancias.

$\mathrm{E}$ as circumstancias, aqui, são principalmente a raça, o solo, as religiões, a riqueza, os costumes, as tradições e a educação do povo. A educação sobretudo. E' a chave para a solução de todos os problemas sociaes, desde a educação primaria por onde todos começam, através da secundaria com que se lastreia o espirito, até a dos institutos universitarios, onde o homem se habilita para a revelação dos mysterios, onde se apparelha para o desafio dos destinos, e onde se apruma para a dignidade da vida.

Bem haja, pois, os que idearam e fundaram a Universidade de São Paulo. Bem haja os que não lhe regateiam os elementos com que não se estiole na flôr murcha e triste dos carrascaes esmarridos.

Quando acceitei a regencia da cadeira de direito politico, na Faculdade de Philosophia, Sciencias e Letras, foi com o pensamento de, ainda aqui, servir, como possa, a minha patria, servindo a Universidade. Farei aqui, como na cathedra que professo na Faculdade de Direito. Alli, nunca restringi o ensino a um bate-bocca de doutrinas em prédicas frias, ou exposições dogmaticas. Mais do que saber o que os outros pensem, importa saber por observação propria, quando não se alcance o "saber só de experiencias feito".

Dahi, a preoccupação preliminar e absorvente dos methodos com que se hão de estudar os phenomenos sociaes. Nesta materia, a confusão é tamanha, que não se entendem ainda hoje os sociologos ao menos sobre o que seja um facto social, sobre a sua natureza intima, os elementos intrinsecos de sua existencia. 


\section{Escola franceza}

Ouçamos, por exemplo, a Dürkheim. Entende elle que dois caracteres essencialisam o facto social.

$\mathrm{O}$ primeiro é a exterioridade aos individuos; factos sociaes são maneiras de agir, de pensar e de sentir, "exteriores" aos individuos, são consciencias collectivas, que não se confundem com as representações individuaes. Ao exercer, por exemplo, sua missão de filho, irmão, esposo, ou cidadão, o homem cumpre deveres que não criou, definidos, antes delle, nos preconceitos, nos costumes, no direito. Ainda mesmo quando estes deveres estão de accôrdo com os nossos sentimentos, e lhes sentimos intimamente a realidade, esta não deixa de ser objectiva. "Quantas vezes, aliás, acontece que ignoramos certos pormenores das obrigações que nos incumbem, e, para conhecel-os, precisamos consultar o codigo e seus interpretes autorisados; da mesma maneira, as crenças e as praticas da vida religiosa: o crente as encontra completas ao nascer". "E, se ellas existem antes delle, é porque existem fóra delle". As maneiras de pensar, de senuir e de agir, em summa, que preexistem e sobrexistem a cada individuo sempre fóra deles, eis os factos sociaes.

$O$ segundo caracter do facto social, para esta escola, é o poder coercitivo. Os factos sociaes exercem acção coactiva sobre as consciencias individuaes, isto é, são dotados de um poder de constrangimento, em virtude do qual se impõem aos individuos. Este poder coactor se manifesta por duas formas principaes. Ora é a força physica da policia, que previne ou reprime; ora é a reprovação publica, que intimida com sancções puramente moraes. Mas sempre coacção. Posto não seja o poder coercitivo a unica differença especifica dos factos sociaes, como a racionalidade não o é do homem, elle é sempre a pedra de toque, para verificar se é, ou não, social um facto.

Em resumo, o facto social, para a escola de Dürkheim, é uma realidade exterior aos individuos, e com poder coercitivo sobre elles. 


\section{Concepção integral}

Não nos parece, porém, que esta concepção seja integralmente verdadeira. Não se contesta a impossibilidade dos factos sociaes com individuos isolados. E' igualmente incontestavel que os factos sociaes não nascem, nem perecem com cada individuo. Mas se geram e se desenvolvem na consciencia dos homens. Sem os individuos, elles são nada. Se não são criados por este ou aquelle individuo, foram surgin'do, e se vão avolumando, pouco a pouco, por influencias individuaes, através das gerações successivas. Não é producto de um individuo; mas o é de todos, em conjuncto. Então, porque, ao nascer, já encontrei a linguagem, a religião, o direito, hei de concluir que o direito, a religião, a linguagem não estão em mim, são realidades fóra dos individuos? Não nos parece de todo certo. $\mathrm{O}$ direito, a religião, a linguagem, por exemplo, existem realmente fóra de mim, mas tambem existem em mim. Quando fóra de mim, como antes do meu nascimento ou depois de minha morte, não estão simultaneamente fóra de outros homens. Estão sempre dentro de individuos, sem serem productos exclusivos de cada um, nem perecerem com qualquer delles.

O que, em verdade, caracterisa o facto social, é não poder elle existir em nenhum individuo, sem o concurso de outros individuos. E' sempre uma relação. Relação de homem para com homens, maneiras de pensar, de sentir e de agir, que resultam da coexistencia humana, de influencias reciprocas de homem a homem, e continuadas na corrente das gerações que se succedem. Jamais maneiras puramente individuaes de pensar, sentir ou agir. Em logar da exterioridade aos individuos, o que constitue a essencia privativa do facto social é ser elle uma relação de homem para com homem.

Exemplifiquemos. O jogo. E' um facto social. Mas em que consiste? Trata-se do jogo de roleta. O que banca, promette pagar dezenas de vezes a quantia jogada no numero 
que der. O que joga, arrisca a ficha em certo numero, na espectativa de lhe ser dadivosa a sorte. Eis ahi uma relação de homem para com homem, um accôrdo de vontades que vincula, criando exigencias e obrigações. Sem duvida, antes de existirem os dois individuos, que figuramos, o jogo já existia, e, por certo, existirá depois que elles se forem. E' superior a estes dois individuos, como a quaesquer outros. Mas, antes delles, já era relação entre individuos; e, depois delles, irá constituir-se, igualmente, de relações entre novos individuos. Sempre relações humanas, e não exterioridades aos individuos.

\section{Antecedentes e consequentes}

Mais ainda. Além de relação humana, o facto social só se pode considerar completo, quando entrelaçado em antecedentes e consequentes. Os antecedentes em si nem sempre são factos sociaes, e os consequentes tambem. Mas só se póde haver por phenomeno social na sua inteireza o complexo de uns e outros em relação de causalidade.

A sociologia é sciencia; mas sciencia é systema de leis, e se lei é a relação constante entre antecedentes e consequentes, onde quer que não se verifiquem antecedentes e consequentes, não se poderá subir até as leis, e, pois, não haverá sociologia. Não basta, por conseguinte, para se haver com um facto social, susceptivel de lei, para se ter um phenomeno social integral, sem o só antecedente, nem o só consequente. Haver por phenomeno social só um, ou só outro, seria mutilar a realidade.

Complexidade semelhante se dá com outras sciencias. Trata-se, por exemplo, do apparecimento de chloro e hydrogenio com a passagem de uma corrente electrica numa solução de acido chlorhydrico. Quem se limitasse a observar esta passagem, suppondo lidar com o phenomeno integral, teria do phenomeno uma idéa erronea, falsa e falha. E' necessario, para lhe conhecer a lei, além de verificar que a decomposição se opera com a dissolução do acido na agua, obser- 
var os effeitos da passagem da corrente electrica. Verificará o apparecimento de chloro num polo e de hydrogenio no outro, em volumes iguaes e pesos differentes. Sem relacionar este resultado com as causas, o phenomeno aqui observado não seria completo. Como este, qualquer phenomeno chimico é relação entre antecedentes e consequentes.

Por que, então, em sociologia, ha de o observador mutilar o phenomeno social, quando lhe investiga as leis? Quer, por exemplo comprehender o phenomeno do divorcio. Ha uma separação entre marido e mulher. Mas a separação em si não é o phenomeno completo. A que lei este facto isolado nos poderia levar? A nenhuma. E' preciso observar as consequencias da separação dos conjuges, consequencias na educação dos filhos, cujo lar se quebra, na situação economica, de que a vida não prescinde, no bem estar de todos, á maneira de cada qual. A separação dos casaes e as suas consequencias é que constituem juntas, o phenomeno social completo. Se se puder fixar a relação constante entre antecedente da separação e os resultados que lhe decorrerem, terse-á então a lei. Muitas vezes, o problema se complica, porque as consequencias do facto, no caso, o divorcio, não são as mesmas, conforme o ambiente social; ellas variam com a raça ou indole dos conjuges, os preconceitos, as religiões e as circumstancias que tracem os contornos, o relevo e a côr de dada sociedade. Mas, no mesmo ambiente, na mesma civilisação, na mesma indole racial, ha de haver certa con-stancia entre o distracto do casamento e os seus effeitos na educação dos filhos, na economia domestica, na consideração publica, no bem estar dos interessados.

Será preciso exemplificar mais? O phenomeno social é um complexo de relações humanas, e as relações entre estas relações são as leis.

\section{Confluencia de causas}

O phenomeno se complica ainda mais pela confluencia das causas. As relações humanas que constituem os factos sociaes, são actividades de homens para com homens. 
Mas as actividades humanas são execuções do que se haja deliberado, e as deliberações resultam do que se pense e sinta. Pensar envolve a capacidade de perecber e de raciocinar.

Ora, sabe-se que a capacidade de ver, ou perceber, e a de prever, ou raciocinar, se baseiam em dados dos sentidos falliveis. Sabe-se que, na elaboração mental, nem sempre o espirito se liberta na phantasia criadora. De modo que a visão e a previsão podem, a cada momento, estar truncadas, erradas, ou ser phantasias.

Ha homens a quem a cultura, o habito da observação, c qualidades pessoaes ensejam menor fallibilidade no pensamento, de modo que uns vêem e prevêem mais e melhor que outros. Mas todos podem errar no que pensam.

Com maiores razões, no aspecto dos sentimentos, dos instinctos, dos habitos, que levam o homem a transvios maiores. As forças impulsivas ou inhibitorias chegam, ás vezes, a cegar. Poucos, os que têm completo dominio sobre suas paixões. Ora, a actividade de homens sobre homens, elemento constitutivo do facto social, resulta de intelligencias precarias, habitos por vezes desorientados, e sentimentos parciaes e perturbadores.

Dahi a diversidade, não raro desorientadora, das circumstancias em meio das quaes se processam os factos, impedindo que, em cada phenomeno, se nos depare uma causa simples. O que se encontra quasi sempre, é uma confluencia de causas, causas por vezes innumeraveis, que difficultam, até ás raias da impossibilidade, a investigação feliz das leis.

\section{Factos contradictorios}

A complexidade dos phenomenos se aggrava com as variações da consciencia individual. Supponha-se a educação moral, que é um dos factos sociaes mais de preço.

São dois paes que seguem systemas differentes na formação de seus filhos. Um delles agiu de tal modo, que o filho se perverteu, ou se desfibrou. O outro, ao contrario, lo- 
grou fazer do filho um homem de acção, energíco, firme e de bem. Eis ahi dois modos de acção social, produzindo duas consequencia oppostas. Ambos os autores das acções educativas pretendiam lograr a formação moral de crianças, que educavam. Admittindo a equivalencia das circumstancias, como serem os educandos da mesma edade, da mesma capacidade e da mesma indole, como as acções sobre elles exercidas foram differentes, os resultados dellas foram o amesquinhamento de um, e o ennobrecimento de outro. Isto é o que se observa todos os dias.

Ao sociologo cabe verificar as relações constantes num e noutro caso. Registrando as duas leis, não sahirá da realidade objectiva. Verificará o que ha, tal como é.

\section{Classificação dos factos}

Mas não poderá negar a differença dos dois casos, na apparencia iguaes, mas contrarios na essencia. Quando o educador age sobre o educando, respeitando-lhe as leis cerebraes, os resultados são favoraveis ao desenvolvimento do educando. Quando, porem, na sua acção educativa, o educador põe o seu arbitrio contra as leis naturaes, o pobre do educando sae prejudicado, em vez de beneficiado. Não póde o sociologo diante de factos do mesmo genero, mas de especies differentes, deixar de catalogal-os em grupos differentes. De um lado, os que attendem ás necessidades da conservação e desenvolvimento da sociedade, e, do outro lado, os que lhe contrariam as leis da conservação e desenvolvimento. E' assim que certos factos sociaes são rotulados de crimes, e outros de direito; são uns normaes, e outros pathologicos.

Sociologos, como o proprio Dürkheim, proclamam a importancia da classificação dos factos sociaes, á luz da normalidade. As duas ordens de factos são estas:

1..$^{\circ}$ os que são tudo o que devem ser, os phenomenos normaes, $\mathrm{e}$

$2 .^{\circ}$ os que deveriam ser differentes do que são, os phenomenos pathologicos. 
O grande embaraço está em acertar com o criterio da normalidade.

Dürkheim tem como criterio dos factos normaes, em primeiro logar, a generalidade do phenomeno, segundo "as condições geraes da vida collectiva no typo social considerado", e, em segundo logar, a sua conformidade com "parte média e immutavel do senso moral".

Esta doutrina nos parece, porém, deixar o problema nas mesma incognitas. São phenomenos geraes o homicidio, o roubo, a mentira, a traição, a venalidade, e todos elles são pathologicos. Logo a generalidade não caracterisa o facto normal. Nem tão pouco se póde definir a normalidade, invocando a conformidade com o senso moral immutavel. O mesmo seria definir o homem como o ser humano. Que é o senso moral immutavel? Não será a intuição profunda do normal?

Ha quem tenha por normal as médias humanas, segundo as condições peculiares de cada agrupamento social.

Não nos parece certo. Nas sociedades em decadencia a média é pathologica, e a excepção é que seria normal.

o que nos parece criterio para classificar os phenomenos sociaes em normaes ou pathologicos é a sua conformidade ás leis ou condições da vida humana. Ser, ou não, gerar um facto, nada colhe. Importa, porém o seu respeito ás leis da vida individual e social, isto é, da vida humana. A perfidia, o furto, o homicidio, por que hão de ser factos pathologicos, senão porque contrarios á conservação e desenvolvimento dos homens? A lealdade, o respeito ao trabalho e á vida dos outros, do outro lado, não são factos normaes, senão porque conformes ás leis da co-existencia humana. Assim como o homem normal é o que exerce sua capacidade de adaptação ás leis da vida, os factos normaes são os que respeitarem as condições de vida e desenvolvimento da sociedade.

Tenha-se, porém, este ou outro criterio selector, as differenças especificas dos factos sociaes nos levam a classifical-os em dois grupos: os que favorecem a integração social 
e os que contribuem para a desintegração social. Os primeiros são, e devem ser. Os segundos, ao contrario, são, mas deveriam ser differentes do que são.

Sem esta classificação geral, o sociologo não poderia comprehender os factos sociaes em toda a sua plenitude. Não que lhe cumpra doutrinar o que deve ser, contraposto ao que seja. Tanto o que deve ser, como o que não deve ser, "são". Trata-se de phenomenos com existencia propria, realidades objectivas. Se o grupo do que deve ser se constituisse de sêres fóra das realidades, ficções, chimeras, ideaes ou duplas, claro está que a sciencia teria sido posta á margem. Mas trata-se de phenomenos sociaes, que de outros decorrem, e que geram novos. Todos, realidades objectivas que se podem observar. O homicidio "é", "existe", é phenomeno social de todos os dias; da mesma forma, o respeito á vida alheia. A perversão pedagogica é facto observavel; da mesma forma, a educação moral. A hypocrisia, a adulação, a falsidade preexistem a este ou áquelle individuo, e sobrevivem indefinidamente a cada qual da mesma forma, a lealdade, a polidez e a sinceridade. São todos factos sociaes. Mas differentes entre si, nos attributos especificos. Dahi, as suas classificações, e entre estes, a distinção por excellencia, em qualquer dos ramos da sociologia, em factos normaes e factos anormaes, entre o que é, e deve ser, e o que é, mas não deve ser.

\section{Leis psychologicas}

Ainda algumas outras consequencias da interferencia dos individuos nos factos sociaes. Embora não sejam elles productos exclusivos da vontade deste ou daquelle individuo; embora existam antes e acima dos arbitrios individuaes, e sobre os individuos actuem com força mais ou menos coactora, pode cada individuo levar ou atirar a sua pedra na construcção ou na destruição dos factos sociaes. E' conhecida a acção de certos homens, substituindo ou reformando instituições, a acção dos conductores de guerra, agitadores e revo- 
lucionarios até por indole. Não só inter-agem o facto social e a vontade individual, como, na sua genese e desenvolvimento, são os factos sociaes criação de vontades humanas através das gerações, sob a pressão irresistivel das necessidades da vida.

Como producto dos homens, posto, em cada momento, superiores ás vontades do individuo, os phenomenos sociaes estão sujeitos ao imperio incontrastavel de leis psychologicas. Ao contrario dos physicos ou astronomicos, os phenomenos sociaes se prendem a uma causa psychologica, a certas consciencias que actuam como causa da acção do individuo na trama das relações sociaes. Quando duas pessoas se associam num negocio, o que principalmente as move é a previsão do lucro. Não importa que o contracto travado seja disciplinado por leis obrigatorias. $O$ certo é que, sem a acção individual, o phenomeno do contracto desappareceria. E esta acção individual tem uma finalidade, na hypothese: a esperança do lucro. Quando um operario contracta, numa fabrica, os seus serviços, o que impulsiona as vontades contractantes é a previsão de vantagens economicas. Quando alguem pratica um acto de benemerencia, o que o inspira, se não foi a preoccupação de nomeada, foi o desejo da consideração publica, ou a satisfação do bem pelo bem. Sempre a consciencia de um fim, que actua, no momento, como causa da interferencia dos individuos na producção do facto social.

Nem sempre se alcança o fim, desejado. Entra alguem numa revolução com o fito de um saneamento politico, e o que della resultou, foi o aggravamento dos males contra os quajes foi deflagrada. Organisa-se uma sociedade anonyma, para a exploração de certo commercio, e antes de qualquer dividendo, ella falliu. As consequencias daquella rebeldia e desta associação foram contrarias ás finalidades previstas, cujas consciencias actuaram como motores dos factos. Nem por isto a consciencia de um fim deixou de existir. Tramam dois bandidos assalto nocturno á residencia de um millionario, ou promove um povo guerra de con- 
quista. O que, nas duas hypotheses, os agita, é a previsão de certas vantagens economicas. Aconteceu, porém, que o assalto não surtiu o effeito esperado, porque foram presos os assaltantes, ou não puderam carregar os objectos furtados. Da mesma fórma pode ter sido mal succedido na sua empresa o povo conquistador, diante da resistencia heroica do povo contra o qual se levantou em armas.

Em qualquer hypothese, na composição dos phenomenos sociaes, os factos antecipam ás leis psychologicas das finalidades que os inspiraram. Nenhum phenomeno social se isenta destas leis. 0 estudo independente dellas, será sempre incompleto, manco, falho. A realidade social ficará, na concepção do observador, desfalcada de um de seus elementos, forjando-se, dest'arte, um mundo differente do real, e impossibilitando a comprehensão do phenomeno em sua plenitude.

\section{Parcialidade do observador}

Toda esta complexidade exige do sociologo o maximo rigor logico de suas observações. A parcialidade de observador é um tapa-olhos tenaz. Aquelle que, no exame da realidade, leva de caso pensado o proposito de contradizer seja como fôr, ou de enquadrar as realidades nas crenças que apostole, jamais verificará as leis das realidades que observar. Grande parte da literatura politica é obscura, tergiversante e esteril, porque os seus autores se preoccupam mais com demonstrar theses do que espelhar fielmente a realidade dos factos. Falta aos seus autores o espirito scientifico, na sua repulsa ao imperio de idéas preconcebidas. A imparcialidade que cumpre, está em ver, registar e testemunhar as coisas como são. As opiniões "a priori" devem ceder o logar ás conclusões "a posteriori". Ao observar os factos, é natural que se formulem hypotheses, se admittam supposições, se tomem attitudes provisorias, que a experiencia confirmará ou infirmará. Mas deixaria de ser imparcial o observador que se obcecasse em demonstrar a sua hypothese, 
a sua idéa preconcebida, a theoria de que estivesse convencido. O que deve é acceitar as conclusões, sejam quaes forem, a que a observação das realidades o conduzir.

\section{Experiencias perigosas}

Certo, não é para qualquer observar com rigorosa logica os phenomenos sociaes. Não se pódem elles encerrar num laboratorio e provocar-lhes experiencias, como em chimica. Trata-se de relações humanas, que se processam em toda parte, através dos tempos, e cujas experimentações podem gerar males e hecatombes irreparaveis.

\section{Observação indirecta}

Para conhecer muitos delles, é preciso lançar mão dos testemunhos, dos documentos, das estatisticas. A observação, aliás, que predomina, é a indirecta, e, dahi a necessidade de escoimar, com redobrada cautela, os dados que nos chegam ao conhecimento. Pódem elles estar inquinados de parcialidade. Pódem ser incompletos, mal observados, ou mal contados. Quasi sempre a realidade real é differente da noticia que della se tem. Quem póde assegurar a verdade liquida de qualquer versão sobre factos de épocas remotas? As interpretações dos historiadores não admira que muitas viezes divaguem, se, raramente chegam dois homens a se entender bem sobre factos contemporaneos, ainda quando sejam delles testemunhas de vista. E sem os dados imprecisos e cambiantes, da observação alheia, ninguem logra conhecer e comprehender com inteireza os phenomenos sociaes.

\section{Processos de inferencia}

Releva ainda observar o maior numero possivel de factos, confrontar entre si os dados das observações alheias, e estes 
com os que tivemos, de observação pessoal; levar em conta a parcialidade maior ou menor dos observadores; dar os descontos da fragilidade mental do homem, aggravada pela complexidade das causas, pelo embaraço em dar com ellas, pela neutralisação de umas por outras, e pelo fugidio com que, ás vezes se apresentam ao olhar, ainda quando arguto, do observador.

Nenhum facto social, como já notámos, decorre de uma causa simples. Os antecedentes costumam ser numerosos, as circumstancias em perpetua variação, causas multiplas quasi imperceptiveis, ou furtacores, desfecham os mesmos resultados, as mesmas consequencias. Isolar num phenomeno, um facto antecedente, em meio dos factos coexistentes, para verificar o consequente que subsiste com a eliminação dos demais antecedentes, e, então, considerar o antecedente que se isolou como causa do consequente que não desappareceu, é dos trabalhos mais arduos em sciencia. social.

A investigação tambiem se poderia realisar por outro processo. Se um antecedente pôde ser excluido, permanecendo o consequente, já se póde concluir que este antecedente e este consequente não estão relacionados por causação, nenhuma relação de causa os liga. Mas se a eliminação de um antecedlente é acompanhada pelo desapparecimento do consequente, a conclusão logica é haver, entre elles, relação de causalidade. Observa-se, por exemplo, que onde nalidade. As condições economicas, o grau de educação se absolvem por systema os criminosos, augmenta a crimipublica, a indole do povo e seus costumes podem influir na criminalidade. Mas se a circumstancia da absolvição systematica subsistir, verifica-se invariavelmente o augmento da criminalidade. Logo, entre este facto e aquelle, ha uma relação de causalidade.

Ainda, além do methodo da concordancia e da differenca, se poderia, em certos casos, applicar o processo das variações concomitantes. $O$ augmento ou a diminuição de 
certo antecedente, num complexo de causas, determina o augmento ou diminuição do consequente, num agglomerado de effeitos. Logo se acham este e aquelle ligados por causação. Um phenomeno, assignala Stuart Mill, que varia de certo modo todas as vezes que outro varia do mesmo modo, é ou a causa, ou o effeito deste phenomeno. Supponham-se a offerta e a procura de um producto, e o seu preço. Se augmenta a offerta, ou diminue a procura, mercê da abundancia do producto, o seu preço desce. Se rareia a offerta ou cresce a procura, pela escassez do producto, o seu preço sobe. Podem outras circumstancias intervir, como a diminuição da capacidade acquisitiva dos consumidores. Neste caso, ainda que escasseie o producto e decresça a offerta, pode o preço não se elevar. Mas, mantidas as mesmas circumstancias, as variações da offerta ou da procura, determinadas pela abundancia, ou escassez de certo producto a venda, são seguidas das variações, no mesmo sentido, do preço deste producto. Logo é de causalidade a relação entre o preço das coisas, e a sua maior offerta e menor procura, ou maior procura e menor offerta.

Em summa, os processos de investigação scientifica em sociologia são, até certo ponto, os mesmos das sciencias biologicas: a observação imparcial, a suggestão das hypotheses, comparações dos factos, a influencia das leis.

Mais ainda. Os phenomenos sociaes se distinguem dos outros por elementos especificos, e, por isso, o methodo da sociologia tem de se adaptar a estas differenças. A maior dellas é a consciencia dos fins, como força propulsora dos factos. Por isto, em sociologia, além da sequencia dos factos, se impõe á consideração do scientista a finalidade psychologica, que os promove.

As sociedades humanas são organisações de pessoas para a obtenção de fins communs, em beneficio de cada qual. Os factos sociaes nascem para beneficiar homens; firmam-se em costumes ou instituições, para o bem collectivo, e não para a desgraça e anniquilamento do homem. 


\section{Utilisação das leis}

Não é sem replica a doutrina de que a sciencia nada tem que vêr com a possivel utilisação de suas leis. Certo, a sciencia pura é desinteressada, e não é porque em nada possa favorecer os homens, que um systema de leis deixe de ser sciencia. Mas não se investigam leis, senão para o seu ulterior aproveitamento. 0 homem aprende para melhor viver. Sem condicionar a sciencia a fins utilitarios, a sociologia não se concebe sem a consciencia dos objectivos, sem a previsão dos fins, como elemento intrinseco, seja qual fôr o phenomeno social. Normalmente, os fins revistos, ou queridos, tendem a bemfazer aos homens. Póde acontecer que os beneficios previstos sejam em favor de uns contra outros. Como pode acontecer que o objectivo de certos phenomenos communs nas sociedades humanas seja insinuar discordias, semear maleficios, ou promover catastrophes. Mas sempre, em todo facto social, a consciencia dos resultados é a causa primaria, a que se juntam factores de emergencia, circumstancias occasionaes, que a reforcem, ou a enfraqueçam.

\section{Sciencia e não Arte}

A consideração da consciencia dos resultados nos factos sociaes, não reduz, comtudo, a sociologia a um formulario de normas praticas. Continua sciencia e não arte. Os preceitos de acção devem seguir e não preceder á verificação das leis. E a sociologia investiga. Mas investiga, sem mutilar a realidade dos factos. A sociologia é sciencia que comprehende, na sua inteireza, os phenomenos sobre que recae, em logar de theorias sobre elementos dispersos, ou aspectos isolados destes phenomenos. Em outra qualquer sciencia, ter-se-á dito quanto baste, dizendo-se "como" se produzem os factos. Nas sciencias sociaes, porém, não basta o "como", senão tambem o "para que", como bem accentuou Ihering. Para que a linguagem, para que a instituição da 
familia, para que os tratados e as guerras, para que a religião, ou o Estado? Todos estes phenomenos visam fins, buscam propositos, se determinam pela consciencia dos resultados. E esta consciencia é parte integrante no phenomeno social. As leis da vontade humana lastreiam a sociologia.

Como se vê, o methodo de investigação nas sciencias sociaes não se distancia grandemente do de qualquer outra sciencia. Em duas coisas se afasta. E' na consideração dos fins, e na classificação dos factos em normaes ou pathologicos, segundo se conformem ou contrariem as leis de conservação da sociedade.

Estarei, acaso, quando assim me exprimo, nas penumbras de uma illusão, alheio ao senso realista da vida?

Não creio, e porque estou certo de que penso, affirmo. Affirmo e examino.

E' a maior homenagem que se pode, neste momento, prestar á Universidade de São Paulo. Laboratorio que já começa a ser, do pensamento nacional, ha de ella contribuir para o desenvolvimento da philosophia da sciencia que, na sua universalidade, não assenta marcos no espaço, nem no tempo. O caminho está traçado no decreto que a criou, e, se nelle perseverarmos, a Universidade de São Paulo hombreará, um dia, com as que mais brilho espalhem pelo mundo. 